\title{
Influence of catalase and pre-freezing equilibration on post-thaw semen quality and conception rate in ewes laparoscopically inseminated
}

\author{
D.R. Câmara ${ }^{1,6}$, L.C. Pinto ${ }^{2}$, M.M.C.M. Pinto ${ }^{2}$, J.P. Kastelic ${ }^{3}$, J.F. Nunes ${ }^{4}$, J.M.P. Barbosa ${ }^{1}$, M.M.P. Guerra ${ }^{5}$ \\ ${ }^{1}$ Laboratory of Animal Reproduction, Federal University of Alagoas, Viçosa, AL, Brazil. \\ ${ }^{2}$ Northeast Biotechnology Network, Fortaleza, CE, Brazil. \\ ${ }^{3}$ Department of Production Animal Health, Faculty of Veterinary Medicine, University of Calgary, Calgary, AB, Canada. \\ ${ }^{4}$ Laboratory of Sheep and Goat Semen Technology, Ceará State University, Fortaleza, CE, Brazil. \\ ${ }^{5}$ Laboratory of Andrology, Federal University of Pernambuco, Recife, PE, Brazil.
}

\begin{abstract}
The aim of this study was to investigate the effects of catalase and pre-freezing equilibration during ram sperm cryopreservation on motility and membrane and acrosomal integrity of frozen-thawed semen, as well as conception rate following laparoscopic timedinsemination. Semen was collected from four mature Dorper rams, pooled and diluted in Tris egg-yolk extender basic solution (CON), or this solution supplemented with catalase $\left(\mathrm{CAT} ; 20 \mathrm{U} / 100 \times 10^{6}\right.$ sperm). Extended semen was packaged in $0.25 \mathrm{ml}$ mini straws $\left(25 \times 10^{6} \mathrm{sperm} / \mathrm{straw}\right)$, chilled (to $\left.5^{\circ} \mathrm{C}\right)$, and then either frozen immediately (CON and CAT) or maintained at $5^{\circ} \mathrm{C}$ for $12 \mathrm{~h}$ of pre-freezing equilibration (CON12 and CAT12). Immediately after thawing and at $1 \mathrm{~h}$ after incubation at $37^{\circ} \mathrm{C}$, kinematic parameters (CASA), plasma membrane integrity (PI-FITC), and acrosomal status (FITC-PNA) of sperm were assessed. There were no significant differences among the four groups on sperm traits evaluated immediately postthaw. However, after $1 \mathrm{~h}$ of incubation, total motility (46.7 and $25.0 \%)$ and plasma membrane integrity $(38.7$ and $25.7 \%)$ were higher $(\mathrm{P}<0.05)$ in CAT12 than CON. When these two treatments were used for laparoscopic timed artificial insemination of ewes (with synchronized ovulation), conception rate was similar for CAT12 and CON (32.8\%, $\mathrm{n}=61$ vs. $27.3 \%, \mathrm{n}=55)$. In conclusion, the combination of catalase and pre-freezing equilibration resulted in significantly improved quality of post-thawed ram semen without affecting conception rate in fixed-time laparoscopically intrauterine inseminated ewes.
\end{abstract}

Keywords: antioxidant, cryopreservation, equilibration time, ram, spermatozoa.

\section{Introduction}

Semen is an inherently complex redox system, with a balance between antioxidant properties of seminal plasma/sperm and the oxidant potential of sperm metabolites, which are particularly activated in non-physiological conditions and control sperm lipoperoxidation rate (Stradaioli et al., 2007). It is noteworthy that low concentrations of reactive oxygen species (ROS) are involved in numerous signaling pathways (Aitken and Bennetts, 2006) that support normal sperm function (Aitken, 1999) without affecting sperm integrity (Wang et al., 2003). However, if the oxidative balance became pro-oxidant, due to excessive ROS production or decreased antioxidant activity, the biological system is under oxidative stress (Sikka, 1996), damaging sperm and reducing fertility (Wang et al., 2003).

Although lipids with gel and fluid phases can co-exist at conventional environmental temperatures, temperature variations modify the physical state of sperm-membrane lipids. The cooling process (during the initial stage of sperm cooling, prior to cryopreservation) causes a transition from fluid to gel phases and decreases membrane fluidity (Holt, 2000), which is probably responsible for thermal shock that may occur at this time. Furthermore, in addition to cooling, sperm must retain their potential viability at $-196^{\circ} \mathrm{C}$ and subsequently overcome stresses associated with thawing (Söderquist et al., 1997). It is believed that pre-freezing equilibration can help sperm reach an osmotic equilibrium following the addition of cryoprotectant (Emmens and Blackshaw, 1955).

In the last few years, we have reported the effects of antioxidants on cryopreserved ram semen (Câmara et al., 2011a; Silva et al., 2011, 2012). Furthermore, we recently reported that catalase and prefreezing equilibration may improve some in vitro aspects of frozen-thawed ram sperm (Câmara et al., 2011b). Although both catalase and glutathione are enzymatic scavengers of hydrogen peroxide, catalase is able to act on higher oxidative stress than glutathione (Baker and Aitken, 2004), presenting a selective action able to reduce lipid peroxidation induced by hydrogen peroxide, but not affecting spontaneous lipid peroxidation in frozen-thawed ram sperm (Maia et al., 2010). It is noteworthy that catalase can act by itself in cases of oxidative stress, whilst the glutathione system depends on a group of cofactors to succeed in its metabolic properties (Silva, 2006). 
Additionally, modern livestock breeding relies on artificial insemination to hasten genetic improvement (Rodriguez-Martinez, 2013b), although in the sheep industry AI is not done universally, due to inconsistent and often low fertility, especially when frozen-thawed semen is used (Anel et al., 2006), which indicate that ram semen cryopreservation still needs improvements (Mata-Campuzano et al., 2015). It is noteworthy that the in vitro benefits of adding antioxidants during sperm cryopreservation were not consistently manifested by improved fertility in vivo. This would be attributed to excessive ROS scavenging, considering that in low concentrations, ROS facilitates normal sperm function (Aitken, 1999), or even due to direct toxic effects of antioxidants (Mata-Campuzano et al., 2012).

Therefore, the aim of this study was to evaluate the effects of catalase and pre-freezing equilibration during semen cryopreservation on motility and on membrane and acrosomal integrity of frozen-thawed ram semen, as well as conception rate following laparoscopic timed-insemination.

\section{Materials and Methods}

\section{Reagents}

All chemicals used were obtained from the Sigma-Aldrich Chemical Company (St Louis, MO, USA).

\section{Rams, semen collection and initial evaluation}

Four 1 to 2 year old Dorper rams, raised in a semi-confinement system with natural light (9.1204 S, $35.7368 \mathrm{~W}$ ), were used. They had ad libitum access to hay and good quality drinking water, and received $400 \mathrm{~g} / \mathrm{head} /$ day of concentrate. All rams were previously deemed breeding sound and were in a semen collection routine three times/week (artificial vagina and teaser female). Ejaculates from all four rams collected on the same day were pooled to eliminate individual differences (Bucak et al., 2008). Minimum requirements to freeze pooled ejaculates were volume $\geq 3.0 \mathrm{ml}$, motility $\geq 80 \%$, and a minimum of $3 \times 10^{9} \mathrm{sperm} / \mathrm{ml}$. Semen was diluted $(1: 200)$ in formol citrate solution, and sperm concentration was calculated using a Neubauer hemocytometer chamber (Menchaca et al., 2005) with bright-field microscopy (400X). These procedures were conducted in quadruplicate, resulting in four pooled semen samples from 16 ejaculates.

\section{Semen processing}

The base extender medium was Tris-egg yolk extender, supplemented with $6 \%$ glycerol and $10 \%$ egg-yolk. Each pool of semen was divided into two equal aliquots and diluted (final concentration, $100 \times 10^{6} \mathrm{sperm} / \mathrm{ml}$ ) with base extender containing catalase $(20 \mathrm{U} / \mathrm{ml}$; CAT) or no antioxidant (control; $\mathrm{CON}$ ). Extended semen was then manually loaded into $0.25 \mathrm{ml}$ mini straws $\left(\mathrm{IMV}^{\circledR}\right.$ Technologies, L'Aigle, Cedex, France) at room temperature, and thereafter immediately cooled $\left(\sim 0.2^{\circ} \mathrm{C} / \mathrm{min}\right)$ to a thermal equilibrium of $5^{\circ} \mathrm{C}$, which was reached within approximately $90 \mathrm{~min}$. Thereafter, half of the doses of each treatment (CAT and $\mathrm{CON}$ ) were placed in a programmable freezer $\left(\mathrm{TK}-3000^{\circledR}\right.$, TK Tecnologia em Congelação LTDA, Uberaba, MG, Brazil), previously equilibrated at $5^{\circ} \mathrm{C}$. Using this machine, semen was cooled from 5 to $-120^{\circ} \mathrm{C}$ at a rate of $12.5^{\circ} \mathrm{C} / \mathrm{min}$. Once straws reached $-120^{\circ} \mathrm{C}$, they were plunged directly into liquid nitrogen for storage. The procedure was repeated with the remaining samples after $12 \mathrm{~h}$ of equilibration at $5^{\circ} \mathrm{C}$ (CAT12 and CON12). Following storage for at least 7 days, straws were thawed at $37^{\circ} \mathrm{C}$ for 30 seconds in a water bath and frozen-thawed semen was evaluated.

\section{Assessment of post-thaw sperm quality using fluorescent} probes

Three straws from each treatment (CON, CAT, CON12, and CAT12) were thawed $\left(37^{\circ} \mathrm{C}, 30 \mathrm{sec}\right)$ and pooled. Immediately and after $1 \mathrm{~h}$ of incubation at $37^{\circ} \mathrm{C}$, membrane and acrosomal integrity were detected using fluorescence probes. The integrity of the sperm membrane was determined using a combination of propidium iodide (PI) and carboxyfluorescein diacetate (CFDA), as described by Harrison and Vickers (1990) and modified by Coleto et al. (2002). Aliquots $(50 \mu \mathrm{l})$ of each sample were diluted in $150 \mu \mathrm{l}$ of Tris containing $20 \mu \mathrm{l}$ of PI $(0.5 \mathrm{mg} / \mathrm{ml}$ in PBS $)$ and $5 \mu 1$ of CFDA $(0.46 \mathrm{mg} / \mathrm{ml}$ in DMSO). Using DBP $485 / 20 \mathrm{~nm}$ excitation and DBP $580-630 \mathrm{~nm}$ emission filters, 200 cells from each sample were examined under an epifluorescence microscope (400X; Carl Zeiss, Göttingen, Germany). Green fluorescence was interpreted as an intact membrane, whereas red indicated a damaged membrane.

For detection of acrosomal integrity, sperm were stained with fluorescein isothiocyanate conjugated with peanut agglutinin (FITC-PNA), as described by Roth et al. (1998). Aliquots ( $5 \mu \mathrm{l})$ of semen from each treatment were placed on microscope slides and airdried. The slides had $20 \mu \mathrm{l}$ of FITC-PNA working solution $(100 \mu \mathrm{g} / \mathrm{ml})$ spread over them, and were incubated at $4{ }^{\circ} \mathrm{C}$ in a moisture chamber for 15 to $20 \mathrm{~min}$ (in darkness). The slides were then immersed in PBS at $4^{\circ} \mathrm{C}$ twice and air-dried in darkness. At the time of evaluation, $5 \mu \mathrm{l}$ of solution containing $4.5 \mathrm{ml}$ of glycerol, $0.5 \mathrm{ml}$ of PBS and $5.0 \mathrm{mg}$ of phenylenediamine was placed on the slide. Then the slide was covered with a coverslip and viewed with epifluorescence (1000X; Carl Zeiss, Göttingen, Germany) using BP 450-490 nm excitation and LP $515 \mathrm{~nm}$ emission filters. Among the 200 cells examined, sperm were classified as having an intact acrosome (iAC) when the 
acrosome region was stained fluorescent green, and as having a reacted acrosome when the fluorescent green was absent from the head region, or when it was present only in the equatorial region of the sperm head.

\section{Computer assisted sperm analysis (CASA)}

Three straws from each treatment (CON, CAT, CON12, and CAT12) were thawed $\left(37^{\circ} \mathrm{C}, 30 \mathrm{sec}\right)$ and mixed. Immediately and after $1 \mathrm{~h}$ of incubation at $37^{\circ} \mathrm{C}$, samples were diluted (1:1) in sodium citrate solution at $2.94 \%(\mathrm{v} / \mathrm{v})$ and sperm motion characteristics were detected by CASA. The latter consisted of an optical phase-contrast microscopy system (Nikon ${ }^{\mathrm{TM}}$ H5505, Eclipse 50i, Japan) with stroboscopic illumination, a warming stage $\left(37^{\circ} \mathrm{C}\right.$ ), video camera (Basler Vision Tecnologie ${ }^{\mathrm{TM}}$ A312FC, Ahrensburg, Germany), and a personal computer with Sperm Class Analyzer ( $\mathrm{SCA}^{\mathrm{TM}}$ ) software (Microptics, S.L., version 3.2.0, Barcelona, Spain). A pre-warmed Makler Chamber ${ }^{\mathbb{B}}$ (Sefi Medical Instrument, Haifa, Israel) was loaded with $5 \mu \mathrm{l}$ of diluted sample; at least four nonconsecutive, randomly selected microscopic fields per sample were scanned, assessing at least 400 motile sperm. Events not related to sperm were excluded, and image sequences were saved and subsequently analyzed. Assessment included the following end points: total motility (TM), progressive motility (PM), curvilinear velocity (VCL), progressive velocity (VSL), and path velocity (VAP). Motility end points were measured with the following settings: temperature $37^{\circ} \mathrm{C}$; frames acquired, 25 ; frame rate, 25 seconds; minimal contrast, 75; frame number, 25 per field; sperm velocity that can be analyzed, 0 to $180 \mu \mathrm{m} / \mathrm{sec}$; and threshold STR, $75 \%$.

Conception rate after laparoscopic artificial
insemination

Multiparous mixed-breed ewes $(n=123)$ raised in an extensive production system with natural light $(9.8498 \mathrm{~S}, 36.1010 \mathrm{~W})$ were used. They had ad libitum access to hay and good quality drinking water. Ewes were ranked according to body condition (BC, 1-5) and age (years) and only ewes with $\mathrm{BC}$ and agee were then allocated into two treatment groups. To synchronize estrus, intravaginal sponges containing $60 \mathrm{mg}$ medroxyprogesterone acetate (Progespon, Syntex, São Paulo, SP, Brazil) were inserted (day 0), with $50 \mu \mathrm{g}$ of a prostaglandin F2 alpha analogue (Ciosin, Schering-Plough Coopers, São Paulo, SP, Brazil) given im on day 9. On day 11, sponges were removed and $250 \mathrm{U}$ of equine chorionic gonadotropin (Folligon, Intervet, São Paulo, SP, Brazil) was given im. Between 56 and $60 \mathrm{~h}$ after sponge removal, fixed-time laparoscopic artificial insemination (LAI) was done in 116 ewes, allocated into two experimental groups $(\mathrm{CON}, \mathrm{n}=55$; CAT12, $\mathrm{n}=61)$ using a single $0.25 \mathrm{ml}$ straw per insemination $\left(25 \times 10^{6}\right.$ sperm/ewe $)$. Immediately before LAI, the straw was thawed $\left(37^{\circ} \mathrm{C}\right.$, $30 \mathrm{sec}$ ) and approximately half of the volume of each straw was placed into each uterine horn (maximum $5 \mathrm{~min}$ after thawing). The same person, working without knowledge of treatment assignment, did all inseminations. Aiming to evaluate the efficacy of the hormonal protocol to induce ovulation, concurrent with LAI, seven ewes submitted to the same estrus synchronization protocol were selectively exposed to rams (deemed breeding sound) for natural service. At 45 days after breeding or insemination, conception rate was determined by transrectal ultrasonography using a $5.0 \mathrm{MHz}$ linear-array transducer in both LAI and naturally bred ewes (CTS 900V, Siui, China).

\section{Statistical analyses}

For in vitro tests (fluorescent probes and CASA), the variables used for comparison purposes were media and pre-freezing equilibration times $(\mathrm{CON}$, CAT, CON12, and CAT12), immediately and $1 \mathrm{~h}$ after thawing. Percentage data were arc-sine transformed prior to statistical analysis (one-way ANOVA, followed by Tukey's test), although all data are reported as nontransformed means \pm SEM. In addition, the same analysis was used to compare, among treatment groups, body condition scores and age of ewes. A Chi-square was used to compare conception rates between treatments (CON and CAT12). For all statistical analyses, results were considered significant when $\mathrm{P}<0.05$.

\section{Results}

There was no influence $(\mathrm{P}>0.05)$ of treatments on sperm traits evaluated immediately post-thaw (Fig. 1 and 2). Although there was a numerical reduction in almost all end points after $1 \mathrm{~h}$ of post-thaw incubation, the addition of catalase resulted in a modest increase in velocity parameters (VCL, VSL and VAP) after $1 \mathrm{~h}$ of incubation (Fig. 2). Furthermore, the combination of $12 \mathrm{~h}$ pre-freezing equilibration and catalase resulted in inferior damage of the sperm plasma membrane ( $\mathrm{P}<0.05$; Fig. 1) and higher total motility $1 \mathrm{~h}$ after thawing compared to the control sample $(\mathrm{P}<0.05$; Fig. 2), cryopreserved without antioxidant and pre-freezing equilibration (38.7 vs. $25.7 \%$ and $46.7 v$ s. $25.0 \%$, respectively). Therefore, samples from CON and CAT12 treatments were used for intrauterine laparoscopic insemination.

After estrus synchronization protocol, all seven ewes that were served by rams became pregnant. The average body condition score and age of inseminated ewes from CON and CAT12 were nearly identical (2.56 vs. 2.55 and 3.72 vs. 3.84, respectively; $\mathrm{P}>0.05$ ) and there was no difference on conception rate on day 45 (day $0=\mathrm{LAI}$ ) between CON and CAT12 (27.3 vs. $32.8 \%$; $>0.05)$ after LAI. 


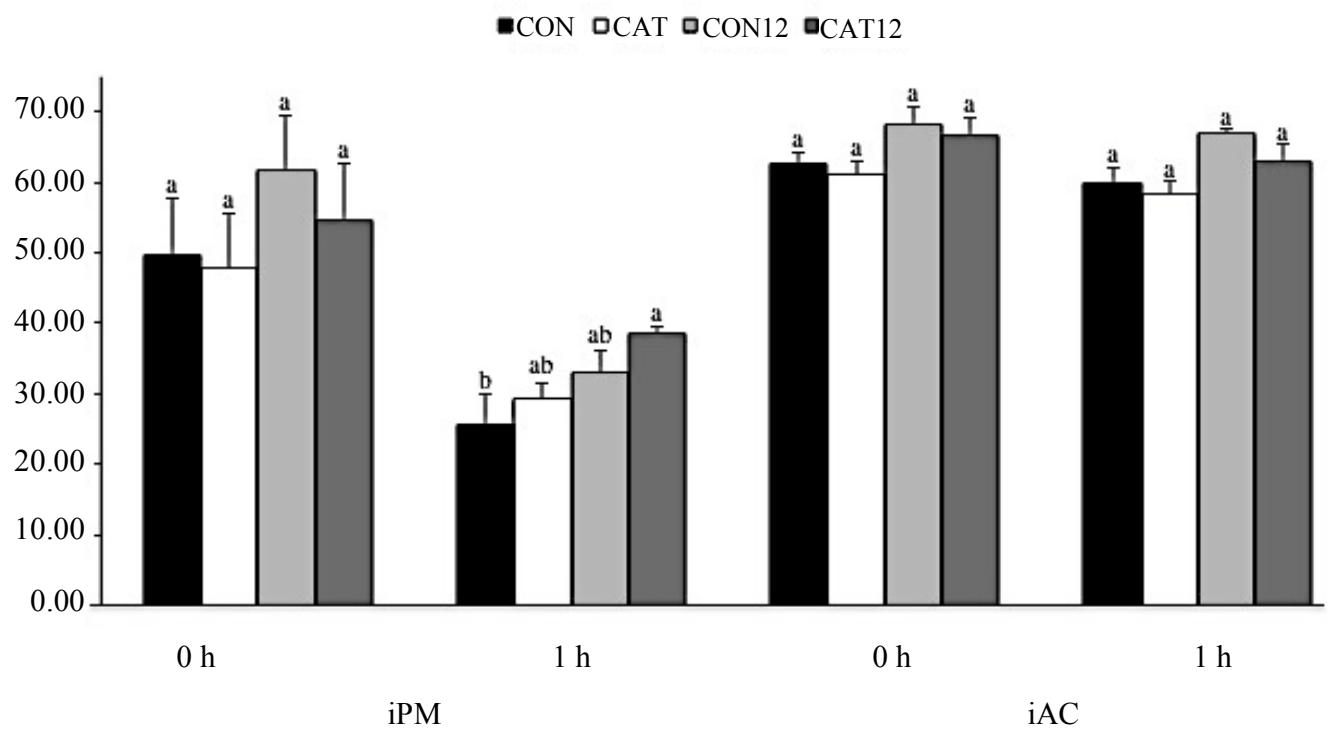

Figure 1. Mean \pm SEM percentages of frozen-thawed ram sperm with intact plasma membrane (iPM) and intact acrosome (iAC) cryopreserved in Tris-egg yolk extender with no antioxidant (CON) or supplemented with 20 $\mathrm{U} / \mathrm{mL}$ of catalase (CAT), and cryopreserved after thermal equilibrium was reached at $5^{\circ} \mathrm{C}$; or $12 \mathrm{~h}$ after equilibration (CON12 and CAT12, respectively). Evaluations were done 0 and $1 \mathrm{~h}$ after thawing.

${ }^{\mathrm{a}, \mathrm{b}}$ Within an end point (iPM, iAC) and time $(0,1 \mathrm{~h})$, means without a common superscript differed $(\mathrm{P}<0.05)$. Data from four pooled semen samples from four rams.

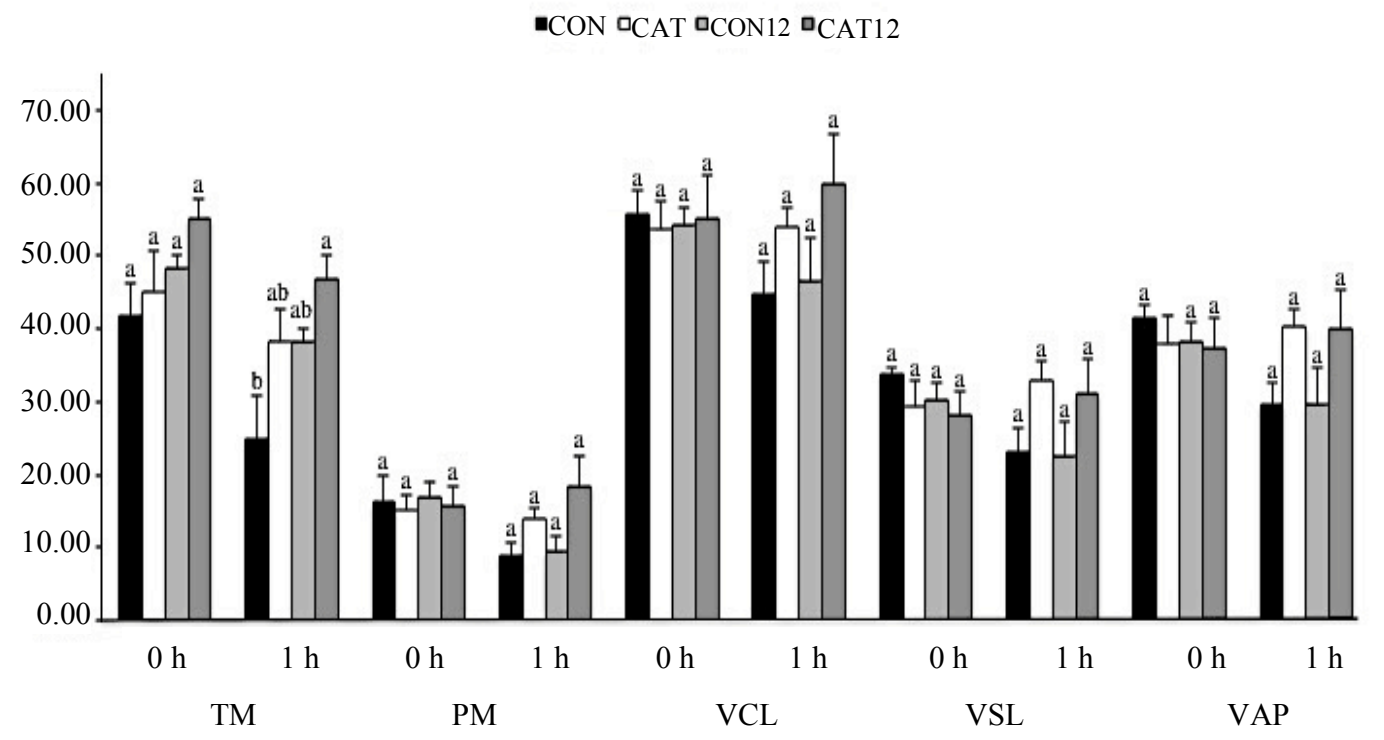

Figure 2. Mean \pm SEM of total motility (TM, \%), progressive motility (PM, \%), curvilinear velocity (VCL, $\mu \mathrm{m} / \mathrm{s}$ ), progressive velocity (VSL, $\mu \mathrm{m} / \mathrm{sec}$ ), and path velocity (VAP, $\mu \mathrm{m} / \mathrm{sec}$ ) of frozen-thawed ram sperm cryopreserved in Tris-egg yolk extender with no antioxidant (CON) or supplemented with $20 \mathrm{U} / \mathrm{ml}$ of catalase (CAT), and cryopreserved after thermal equilibrium was reached at $5^{\circ} \mathrm{C}$; or $12 \mathrm{~h}$ after equilibration (CON12 and CAT12, respectively). Evaluations were done 0 and $1 \mathrm{~h}$ after thawing.

${ }^{\mathrm{a}, \mathrm{b}}$ Within an end point (TM, PM, VCL, VSL, VAP) and time $(0,1 \mathrm{~h})$, means without a common superscript differed $(\mathrm{P}<0.05)$. Data from four pooled semen samples from four rams.

\section{Discussion}

The post-thaw semen quality in the present study has similar motility, higher percentage of viable cells and lower percentage of intact acrosome when compared with data reported by Bucak et al. (2008), who tested other antioxidants besides catalase, although Bucak et al. (2008) did not use CASA or fluorescence technique to evaluate sperm endpoints. When compared to the present study, Câmara et al. (2011b) reported 
similar percentage of sperm with intact acrosome, higher values of sperm motility and VCL, and lower percentage of viable sperm after using a very similar experimental design. We inferred that, in this case, these differences could be related to both individual and seasonal influence on sperm quality and freezability (Simplício et al., 1982; D'Alessandro and Martemucci, 2003; Frazão Sobrinho et al., 2014), since both experiments were conducted using different breeds and year season.

It is well known that cryopreservation causes physical and chemical stresses to sperm membranes, along with oxidative stress, which can reduce sperm viability and fertilizing capability (Watson, 2000), being the sperm damage due to the release of endogenous reactive oxygen species the major cause of reduction in sperm motility and conception rate associated with semen cryopreservation (Bucak at al., 2008). However, the benefits of catalase are not concentration-dependent and excessive concentrations can have a deleterious effect on ram sperm (Maxwell and Stojanov, 1996). We inferred that the catalase/sperm ratio used in the present study $\left(20 \mathrm{U} / 100 \times 10^{6}\right.$ sperm $)$ was appropriate for cryopreservation of ram semen, as it yielded some apparent (albeit not significant) improvements in velocity parameters (VCL, VSL, and VAP) of thawed ram sperm samples after $1 \mathrm{~h}$ incubation, probably due to a biochemical equilibrium between ROS generation and scavenging, supporting physiological aspects of sperm cell metabolism.

The combination of pre-freezing equilibration plus the benefits of catalase addition significantly improved (compared to the control group) percentages of motile sperm and those with an intact plasma membrane after $1 \mathrm{~h}$ of incubation post-thaw. We inferred that the better plasma membrane integrity in CAT12 was due to fewer ultrastructural changes previously reported during ram sperm cryopreservation (Silva et al., 2013), especially considering the sensitivity of ram sperm to cold-shock, apparently due to the cholesterol-phospholipid ratio (Tapia et al., 2012). Results similar to those in the present study were reported for bovine semen (Anzar et al., 2011), with beneficial effects of pre-freezing equilibration on plasma and acrosomal membranes of sperm. These authors stated that during prolonged refrigeration, sperm can probably adapt to the low temperature and enabled egg yolk lipoproteins to more effectively exert their protective effects. However, it is noteworthy that prolonged pre-freezing equilibration did not consistently improve in vitro or in vivo aspects of sperm quality. In this regard, Purdy et al. (2010) reported no improvement with $24 \mathrm{~h}$ of pre-freezing equilibration at $5^{\circ} \mathrm{C}$ on motion parameters or conception rate of ram semen.

Thus, LAI was performed to determine whether the beneficial effects of catalase and prefreezing equilibration time observed in vitro were also manifested as improved in in vivo fertility, since there are many studies reporting in vitro effects of antioxidants during ram semen cryopreservation but with no data regarding its influence on in vivo fertility (Bucak et al., 2008; Maia et al., 2010; Câmara et al., 2011a, b; Silva et al., 2011, 2012, 2013; MataCampuzano et al., 2012, 2014, 2015). The conception rate of seven ewes subjected to hand-mated natural breeding confirmed the efficacy of the hormonal protocol to synchronize estrous and ovulation. For LAI, a reduced number of sperm $\left(25 \times 10^{6} \mathrm{sperm} / \mathrm{ewe}\right)$ were inseminated compared to other reports (Purdy et al., 2010; Alvarez et al., 2012; Richardson et al., 2012; Del Olmo et al., 2013) and the number of motile sperm can directly interfere on the conception rate after LAI (Maxwell, 1986; Eppleston and Maxwell, 1995), which could explain the low conception rate obtained in both groups inseminated. In that regard, our intention was to avoid using a large number of sperm that could potentially mask real differences in sperm quality and function (Eppleston and Maxwell, 1995; Amann and Waberski, 2014) due to compensable sperm defects (Saacke, 2008).

Sperm evaluation immediately after thawing is considered unable to detect sub lethal damage, such as that reported in ionic channels and transmembrane proteins (Tapia et al., 2012), which can affect in vivo conception rates due to alterations in the mechanisms involved in the passage of sperm through the uterotubal junction or perhaps affect the interaction between sperm and oviduct cells (Druart, 2012). Del Olmo et al. (2013) reported a positive correlation among in vivo conception rate of thawed ram sperm and kinematic parameters (VCL, VAP, and BCF) after $2 \mathrm{~h}$ incubation; moreover, sperm plasma membrane integrity had a greater association with conception rate than sperm motility end points (Rodriguez-Martinez, 2013a). However, the benefits detected in this study on motility and membrane integrity in vitro after $1 \mathrm{~h}$ storage post-thaw were not able to significantly increase the conception rate in CAT12 compared to CON, reinforcing that although routine sperm evaluation tests (viability, motility, concentration, sperm morphology) are useful indicators, they cannot adequately predict potential conception rate (Tsakmakidis, 2010), due to the existence of a complex modulation to maintain semen quality and fertility (Rodriguez-Martinez, 2003; MataCampuzano et al., 2015).

In conclusion, the combination of exogenous catalase added to extender medium and a $12 \mathrm{~h}$ prefreezing equilibration at $5^{\circ} \mathrm{C}$ significantly reduced ram sperm cryodamage but did not improve the conception rate of ewes that were laparoscopically timedinseminated.

\section{Acknowledgments}

This research was supported by CNPq. The authors thank the staff at the Varrela Agropecuária (São 
Miguel dos Campos-AL) for allowing us to use their animals.

\section{References}

Aitken RJ. 1999. The human spermatozoa: a cell in crisis? J Reprod Fertil, 115:1-7.

Aitken RJ, Bennets L. 2006. Reactive oxygen species: friend or foe. In: De Jonge CJ, Barrat CLR. The sperm cell - production, maturation, fertilization, regeneration. New York: Cambridge University Press. pp. 170-192.

Alvarez M, Tamayo-Canul J, Anel E, Boixo JC, Mata-Campuzano M, Martinez-Pastor F, Anel L, Paz P. 2012. Sperm concentration at freezing affects post-thaw quality and fertility of ram semen. Theriogenology, 77:1111-1118.

Amann RP, Waberski D. 2014. Computer-assisted sperm analysis (CASA): capabilities and potential developments. Theriogenology, 81:5-17.

Anel L, Alvarez M, Martinez-Pastor F, GarciaMacias V, Anel E, Paz P. 2006. Improvement strategies in ovine artificial insemination. Reprod Domest Anim, 41:30-42.

Anzar M, Kroetsch T, Boswall L. 2011. Cryopreservation of bull semen shipped overnight and its effect on post-thaw sperm motility, plasma membrane integrity, mitochondrial membrane and normal acrosomes. Anim Reprod Sci, 126:23-31.

Baker MA, Aitken RJ. 2004. The importance of redox regulated pathways in sperm cell biology. Mol Cell Endocrinol, 216:47-54.

Bucak MN, Atessahim A, Yüce A. 2008. Effect of anti-oxidants and oxidative stress parameters on ram semen after the freezing-thawing process. Small Rumin Res, 75:128-134.

Câmara DR, Mello-Pinto MMC, Pinto LC, Brasil OO, Nunes JF, Guerra MMP. 2011a. Effects of reduced glutathione and catalase on the kinematics and membrane functionality during liquid storage of ram semen. Small Rumin Res, 100:44-49.

Câmara DR, Silva SV, Almeida FC, Nunes JF, Guerra MMP. 2011b. Effect of the addition of antioxidants and different pre-freezing equilibration times on the quality of frozen-thawed ram semen. Theriogenology, 76:342-350.

Coleto ZF, Guerra MMP, Batista AM. 2002. Avaliação do sêmen congelado de caprinos com drogas fluorescentes. Rev Bras Med Vet, 24:101-104.

D'Alessandro AG, Martemucci, G. 2003. Evaluation of seasonal variations of semen freezability in Leccese ram. Anim Reprod Sci, 79:93-102.

Del Olmo E, Bisbal A, Maroto-Morales A, GarcíaAlvarez O, Ramon M, Jimenez-Rabadan P, Martínez-Pastor F, Soler AJ, Garde JJ, FernandezSantos MR. 2013. Fertility of cryopreserved ovine semen is determined by sperm velocity. Anim Reprod Sci, 138:102-109.

Druart X. 2012. Sperm interaction with the female reproductive tract. Reprod Domest Anim, 47:348-352.

Emmens CW, Blackshaw AW. 1955. The low temperature storage of ram, bull and rabbit spermatozoa. Aust Vet J, 26:226-228.

Eppleston J, Maxwell WMC. 1995. Sources of variation in the reproductive performance of ewes inseminated with frozen-thawed ram semen by laparoscopy. Theriogenology, 43:777-788.

Frazão Sobrinho JM, Branco MAC, Sousa Júnior A, Nascimento IMR, Mota LHCM, Carvalho YNT, Ferreira SB, Costa DNM, Moraes Júnior FJ, Souza JAT. 2014. Characteristics of the semen of Dorper, Santa Inês and undefined breed sheep, pre- and postfreezing, in the rainy and dry period. Arq Bras Med Vet Zootec, 66:969-976.

Harrison RAP, Vickers SE. 1990. Use of fluorescent probes to assess membrane integrity in mammalian spermatozoa. $J$ Reprod Fertil, 88:343-352.

Holt WV. 2000. Basic aspects of frozen storage of semen. Anim Reprod Sci, 62:3-22.

Maia MS, Bicudo SD, Sicherle CC, Rodello L, Gallego ICS. 2010. Lipid peroxidation and generation of hydrogen peroxide in frozen-thawed ram semen cryopreserved in extenders with antioxidants. Anim Reprod Sci, 122:118-123.

Mata-Campuzano M, Álvarez-Rodriguez M, Álvarez M, Anel L, Paz P, Garde JJ, Martínez-Pastor F. 2012. Effect of several antioxidants on thawed ram spermatozoa submitted to $37{ }^{\circ} \mathrm{C}$ up to four hours. Reprod Domest Anim, 47:907-914.

Mata-Campuzano, M, Álvarez-Rodriguez M, Tamayo-Canul J, Lopez-Urueña H, Paz P, Anel L, Martínez-Pastor F, Álvarez M. 2014. Refrigerated storage of ram sperm in presence of Trolox and GSH antioxidants: effect of temperature, extender and storage time. Anim Reprod Sci, 151:137-147.

Mata-Campuzano, M, Álvarez-Rodriguez $\mathbf{M}$, Álvarez M, Tamayo-Canul J, Anel L, Paz P, Martínez-Pastor F. 2015. Post-thawing quality and incubation resilience of cryopreserved ram spermatozoa are affected by antioxidant supplementation and choice of extender. Theriogenology, 83:520-528.

Maxwell WMC. 1986. Artificial insemination of ewes with frozen-thawed semen at a synchronized oestrus. 2 . Effect of dose of spermatozoa and site of intrauterine insemination on fertility. Anim Reprod Sci, 10:309-316. Maxwell WMC, Stojanov T. 1996. Liquid storage of ram semen in the absence or presence of some antioxidants. Reprod Fertil Dev, 8:1013-1020.

Menchaca A, Pinczak A, Queirolo D. 2005. Storage of ram semen at $5^{\circ} \mathrm{C}$ : effects of preservation period and timed artificial insemination on pregnancy rate in ewes. Anim Reprod, 2:195-198.

Purdy PH, Mocé E, Stobart R, Murdoch WJ, Moss GE, Larson B, Ramsey S, Graham JK, Blackburn HD. 2010. The fertility of ram sperm held for $24 \mathrm{~h}$ at $5^{\circ} \mathrm{C}$ prior to cryopreservation. Anim Reprod Sci, 118:231-235. 
Richardson L, Hanrahan JP, Donovan A, Martí JI, Fair S, Evans ACO, Lonergan P. 2012. Effect of site of deposition on the fertility of sheep inseminated with frozen-thawed semen. Anim Reprod Sci, 131:160-164.

Rodriguez-Martinez H. 2003. Laboratory semen assessment and prediction of fertility: still utopia? Reprod Domest Anim, 38:312-318.

Rodriguez-Martinez H. 2013a. Semen evaluation techniques and their relationship with fertility. Anim Reprod, 10:148-159.

Rodriguez-Martinez H. 2013b. Sperm biotechnologies in domestic species: state of the art. Anim Reprod, 10:268-276.

Roth TL, Weiss RB, Buff JL, Bush LM, Wildt DE, Bush M. 1998. Heterologous in vitro fertilization and sperm capacitation in an endangered African antelope, the cimitar-Horned Oryx (Oryxdammah). Biol Reprod, 58:475-482.

Saacke, RG. 2008. Sperm morphology: its relevance to compensable and uncompensable traits in semen. Theriogenology, v.70:473-478.

Sikka SC. 1996. Oxidative stress and role of antioxidants in normal and abnormal sperm function. Front Biosci, 1:78-86.

Silva ECB, Cajueiro JFP, Silva SV, Soares PC, Guerra MMP. 2012. Effect of antioxidants resveratrol and quercetin on in vitro evaluation of frozen ram sperm. Theriogenology, 77:1722-1726.

Silva PFN. 2006. Physiology of peroxidation process in mammalian sperm. 2006. Utrecht, Netherlands: Utrecht University. PhD Thesis. 177 pp.

Silva SV, Soares AT, Batista AM, Almeida FC, Nunes JF, Peixoto CA, Guerra MMP. 2011. In vitro and in vivo evaluation of ram sperm frozen in Tris egg- yolk and supplemented with superoxide dismutase and reduced glutathione. Reprod Domest Anim, 46:874-881.

Silva SV, Soares AT, Batista AM, Almeida FC, Nunes JF, Peixoto CA, Guerra MMP. 2013. Vitamin E (Trolox) addition to Tris-egg yolk extender preserves ram spermatozoon structure and kinematics after cryopreservation. Anim Reprod Sci, 137:37-44.

Simplício AA, Riera GS, Nelson EA, Pant KP. 1982. Seasonal variation and testicular characteristics of Brazilian Somalis ram in the hot semi-arid climate of tropical northeast Brazil. J Reprod Fertil, 66:735-738.

Söderquist L, Madrid-Bury N, Rodriguez-Martinez H. 1997. Assessment of ram sperm membrane integrity following different thawing procedures. Theriogenology, 48:115-1125.

Stradaioli G, Noro T, Sylla L, Monaci M. 2007. Decrease in glutathione (GSH) content in bovine sperm after cryopreservation: comparison between two extenders. Theriogenology, 67:1249-1255.

Tapia JA, Macias-Garcia B, Miro-Moran A, OrtegaFerrusola C, Salido GM, Peña FJ, Aparicio IM. 2012. The membrane of the mammalian spermatozoa: much more than an inert envelope. Reprod Domest Anim, 47:65-75.

Tsakmakidis IA. 2010. Ram semen evaluation: development and efficiency of modern techniques. Small Rumin Res, 92:126-130.

Wang X, Sharma RK, Gupta A, George V, Thomas AJ, Falcone T, Agarwal A. 2003. Alterations in mitochondria membrane potential and oxidative stress in infertile men: a prospective observational study. Fertil Steril, 80:844-850.

Watson PF. 2000. The causes of reduced fertility with cryopreserved semen. Anim Reprod Sci, 60/61:481-492. 